\title{
The Role of the Canadian Media During the Initial Response to the COVID-19 Pandemic: A Topic Modelling Approach Using Canadian Broadcasting Corporation News Articles
}

\author{
Janhavi Patel $^{1^{*}}$, BMSc; Harsheev Desai ${ }^{2 *}$, BS; Ali Okhowat ${ }^{3}$, MD \\ ${ }^{1}$ Michael G DeGroote School of Medicine, McMaster University, Hamilton, ON, Canada \\ ${ }^{2}$ Faculty of Engineering and Architectural Science, Ryerson University, Toronto, ON, Canada \\ ${ }^{3}$ UBC Global Health, Faculty of Medicine, University of British Columbia, Vancouver, BC, Canada \\ *these authors contributed equally
}

Corresponding Author:

Janhavi Patel, BMSc

Michael G DeGroote School of Medicine

McMaster University

1280 Main Street West

Hamilton, ON, L8S 4L8

Canada

Phone: 19055259140

Email: patelj10@mcmaster.ca

\section{Abstract}

Background: Beginning as a local epidemic, COVID-19 has since rapidly evolved into a pandemic. As countries around the world battle this outbreak, mass media has played an active role in disseminating public health information.

Objective: The aim of this study was to get a better understanding of the role that the Canadian media played during the pandemic and to investigate the patterns of topics covered by media news reporting.

Methods: We used a data set consisting of news articles published on the Canadian Broadcasting Corporation (CBC) website between December 2019 and May 2020. We then used Python software to analyze the data using Latent Dirichlet Allocation topic modelling. Subsequently, we used the pyLDAvis tool to plot these topics on a 2D plane through multidimensional scaling and divided these topics into different themes.

Results: After removing articles that were published before the year 2019, we identified 6771 relevant news articles. According to the $\mathrm{CV}$ coherence value, we divided these articles into 15 topics, which were categorized into 6 themes. The three most popular themes were case reporting and testing $(\mathrm{n}=1738)$, Canadian response to the pandemic $(\mathrm{n}=1259)$, and changes to social life ( $\mathrm{n}=1171)$, which accounted for $25.67 \%, 18.59 \%$, and $17.29 \%$ of the total articles, respectively.

Conclusions: Understanding the Canadian media's reporting on the COVID-19 pandemic shows that the Canadian pandemic response is a product of consistent government communication, as well as the public's understanding of and adherence to protocols.

(JMIR Infodemiology 2021;1(1):e25242) doi: 10.2196/25242

\section{KEYWORDS}

COVID-19; topic modelling; LDA; health communication; mass media; coronavirus; media; dissemination; online health information; public health

\section{Introduction}

COVID-19, which started as a local epidemic, evolved into a pandemic in a matter of months [1]. Countries around the world are battling the spread of this disease and the unfortunate consequences of COVID-19-related mortality and morbidity, resource limitations, and severe economic burden $[1,2]$. Canada is no different and continues to observe a rising number of COVID-19 cases [3].

Due to the initial lack of vaccines and knowledge about the disease and its treatment, countries were forced to take unique approaches to combat the spread of the virus. Canada's response has been widely reported as being adequate, though much more could have been and remains to be done in tackling the spread 
of COVID-19 [4]. The Canadian government website for its COVID-19 response highlights the measures Canada has taken, including the creation of the COVID Alert app, an ethics framework for policy makers, and economic support for Canadians. Support involves both financial measures and safety, including for Canadians abroad and vulnerable populations in Canada [3]. Additionally, there has been an emphasis on public education, collaboration, and guidance for researchers and frontline health workers [3].

With the uncertainty surrounding this novel coronavirus, the media-especially online news sources-have played a key role in informing the public about events related to the pandemic. Mass media has been successfully used for decades to increase public health awareness. News media outlets have been used across the globe for addressing public health issues like reducing tobacco use, participating in screening for cancer, and cardiovascular disease prevention [5]. The Eat Well campaign, which was advertised through a combination of news and commercial media outlets, increased awareness about meal prepping and healthy food choices in the Canadian population [6]. A postcampaign evaluation showed that low-resource communities had a greater uptake of information, thus highlighting the need to better understand the impact of different information dissemination campaigns to better cater to the target population [6].

The Canadian Broadcasting Corporation $(\mathrm{CBC})$ is a daily source of local and national information for many Canadians [7]. The CBC's digital offering sees an average of 16.1 million new monthly visits [7] and continues to grow every month. Assessing the content of $\mathrm{CBC}$ articles can therefore provide insights into the information delivered to Canadians about the pandemic. Given that success in the fight against the pandemic greatly depends on the support of the public (eg, maintaining appropriate social distance and taking proper precautions), the information that media outlets report is important as it provides the public with up-to-date guidance.

The aim of this study was to better understand the role that news articles played in disseminating public health information, by specifically focusing on the topics reported and frequency of each topic reported regarding the COVID-19 pandemic. The methods used and results from this study could be relevant when reporting future events related to health care and national safety, which rely heavily on public support and awareness.

\section{Methods}

\section{Data Collection}

The data set was collected from the CBC website using a Python programming language script [8]. The script was used to extract information from over 6700 news articles, including the title, article summary, and main text for each article, using the term "coronavirus" as the search word. The extracted news articles were published between December 2012 and May 2020; however, only the articles published in 2019 and 2020 were included in this study.

We used Latent Dirichlet Allocation (LDA) to analyze these news articles. LDA is a three-level hierarchical Bayesian model, in which each item of a collection is modelled as a finite mixture over an underlying set of topics. The basic idea behind LDA is that documents can be represented as arbitrary mixtures over latent topics, which in turn are characterized by a distribution over words [9]. LDA has been extensively used and evaluated for its applicability in topic modelling research $[10,11]$. Moreover, Lancichinetti [12] showed that LDA has high reproducibility and accuracy for topic classification.

According to LDA, there are diverse topics in each news article, and the words in these articles can be allotted to one of these topics. However, LDA only groups inputs (ie, news articles in this case) based on the abovementioned distribution over words and it is subjective how these groups are interpreted as topics. To facilitate accurate representation, randomly selected articles from each topic were manually checked to make sure they were consistent with the interpreted topic.

\section{Data Processing}

There were a total of 6771 news articles remaining after removing the articles published before 2019. These remaining articles were dated between December 22, 2019, and May 3, 2020.

Before moving forward with topic modelling, we used Python along with libraries, including the Pandas and Natural Language Toolkit (NLTK) libraries [13], to clean the data. The detailed process for this is displayed in Figure 1. We used the English language stop words provided by NLTK to remove common words such as "an," "all," "and," "for," and "from" as they hold no semantic value for our analysis. URLs and social media mentions consisting of "@” were also removed. The two primary inputs to the LDA model are the dictionary and the corpus, which were created using the Gensim library [14]. 
Figure 1. Workflow chart. CBC: Canadian Broadcasting Corporation; LDA: Latent Dirichlet Allocation.

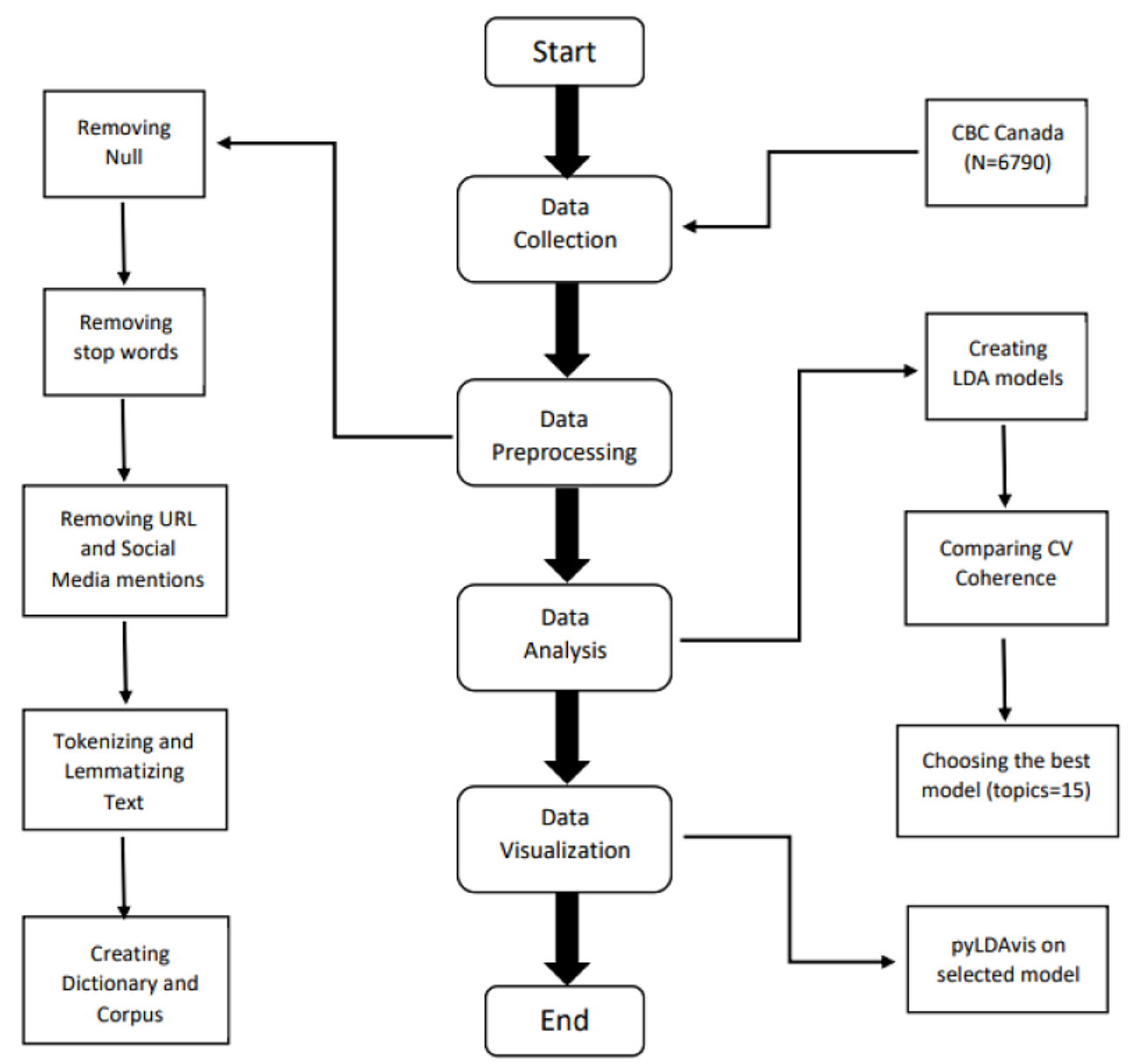

We used the CV coherence score to evaluate models with different numbers of topics and selected the one with the highest CV score. This approach mitigates one of LDA's limitations - the need to know the number of topics ahead of time. According to Röder et al [15], the CV coherence score is one of the fastest measures of coherence, and the most accurate. Henri Trenquier defines coherence as the human's semantic appreciation of a topic represented by its $\mathrm{N}$ top words [16]. We chose the top $15(\mathrm{~N})$ words in each topic to calculate the coherence.

As evident from Figure 2, the highest $\mathrm{CV}$ coherence score was achieved at 15 topics. This means that the top words in each topic were most closely related semantically when the news article data set was divided into 15 different topics using LDA. 
Figure 2. Coherence score for number of topics.

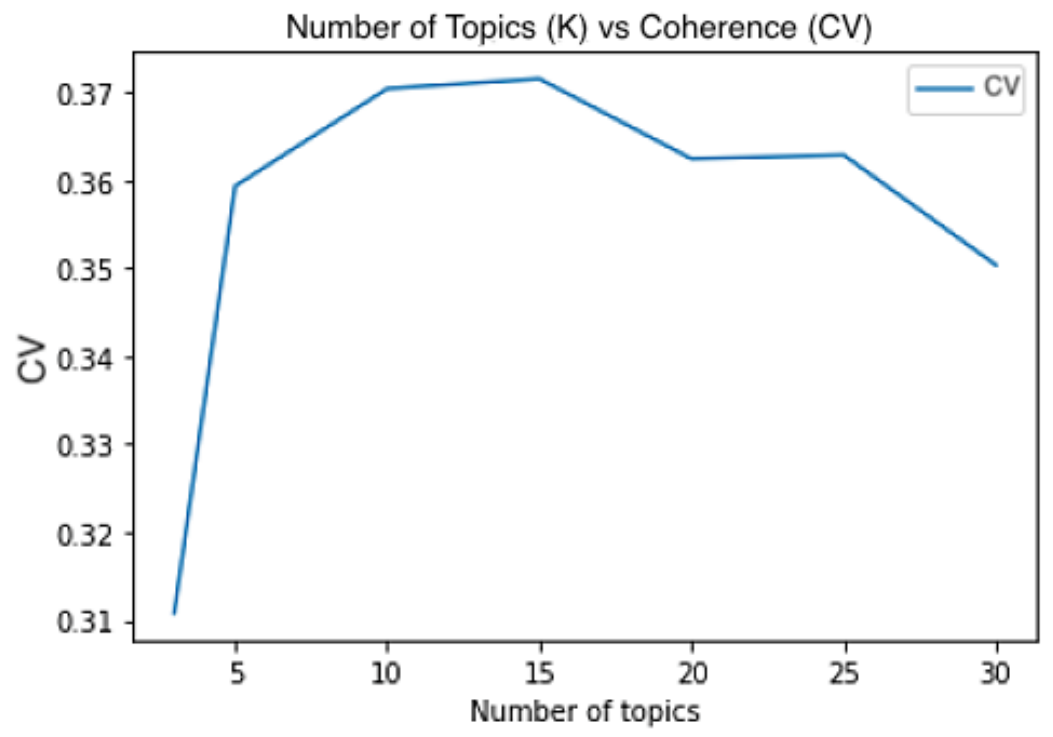

We then used the pyLDAvis tool [17] and Python to further analyze the 15 topics to extract valuable insights from the articles. The 15 topics were represented on an intertopic distance map, which is an interactive representation offered by the

Figure 3. Intertopic distance map.
pyLDAvis tool (Figure 3). The topics are plotted as circles in a 2D plane whose centers are determined by computing the distance between topics [16].

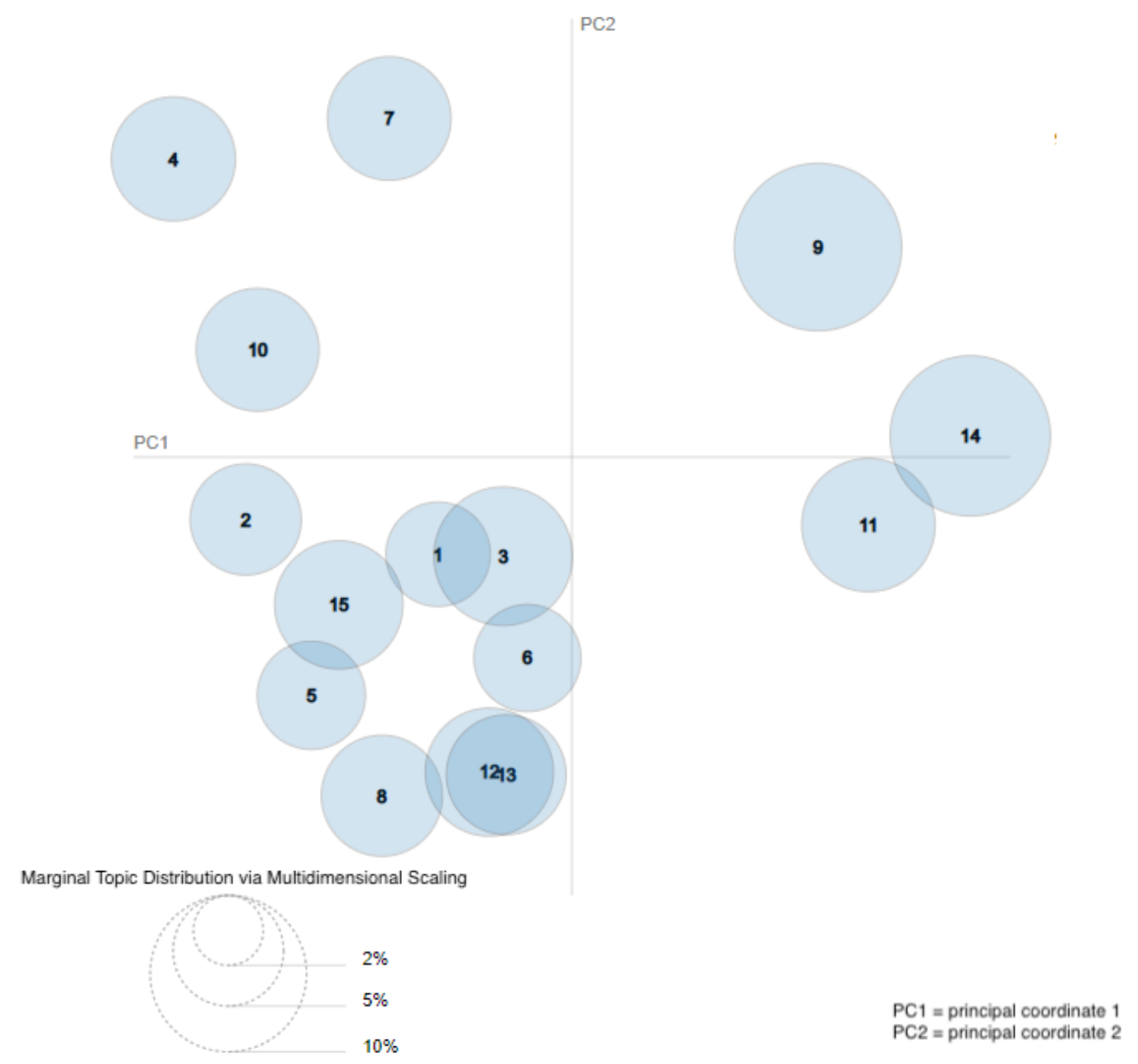


The weight parameter $\lambda$ was adjusted to find the theme for each topic based on the top words in the topic. Setting $\lambda=1$ ranks the words in a topic by frequency, while setting $\lambda=0$ ranks the words based on uniqueness to that topic [17]. We used the interactive bar provided by the pyLDAvis tool to adjust $\lambda$ and understand the theme for each of the 15 topics. To use topic 9 as an example, Figure 4 shows the top 30 most frequently occurring words in topic 9. As multiple topics might have similar words that occur frequently, we need to adjust the $\lambda$ value to better gauge what topic an article might be about. For instance, when we set $\lambda$ to 0.04 , the terms most unique to topic 9 are captured, and presented in descending order in Figure 5. This analysis identifies words like "test," "positive," and "spread" as being unique to topic 9. Using the keywords, we identified that the general theme of articles in topic 9 is "testing." This process was repeated for each topic (Table 1).

Figure 4. Top 30 most relevant terms $(\lambda=1.0)$.

\section{Top-30 Most Relevant Terms for Topic 9 (11.5\% of tokens)}

0

500

1000

1500

2000

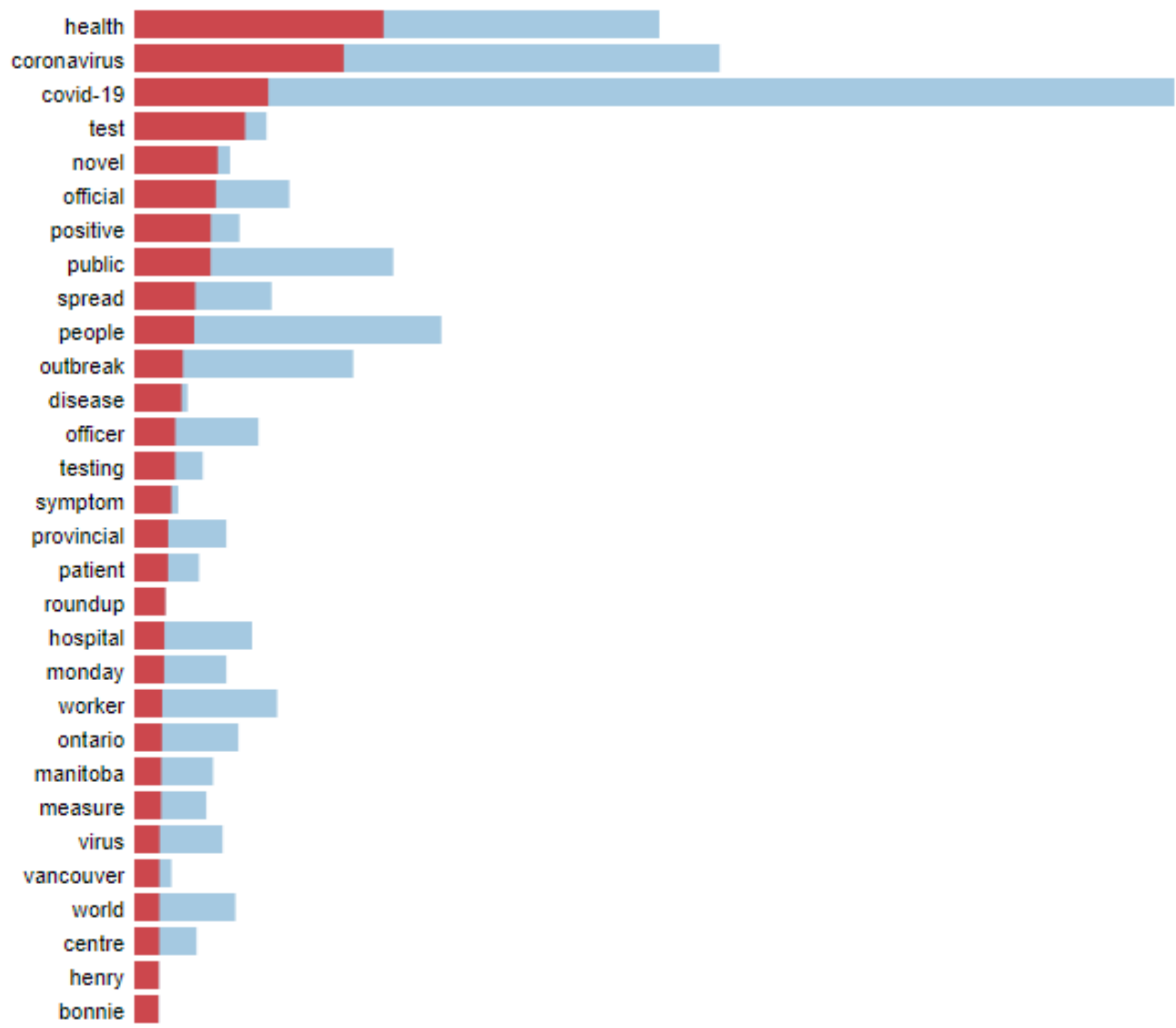

Overall term frequency

Estimated term frequency within the selected topic 
Figure 5. Top 30 most relevant terms $(\lambda=0.4)$.

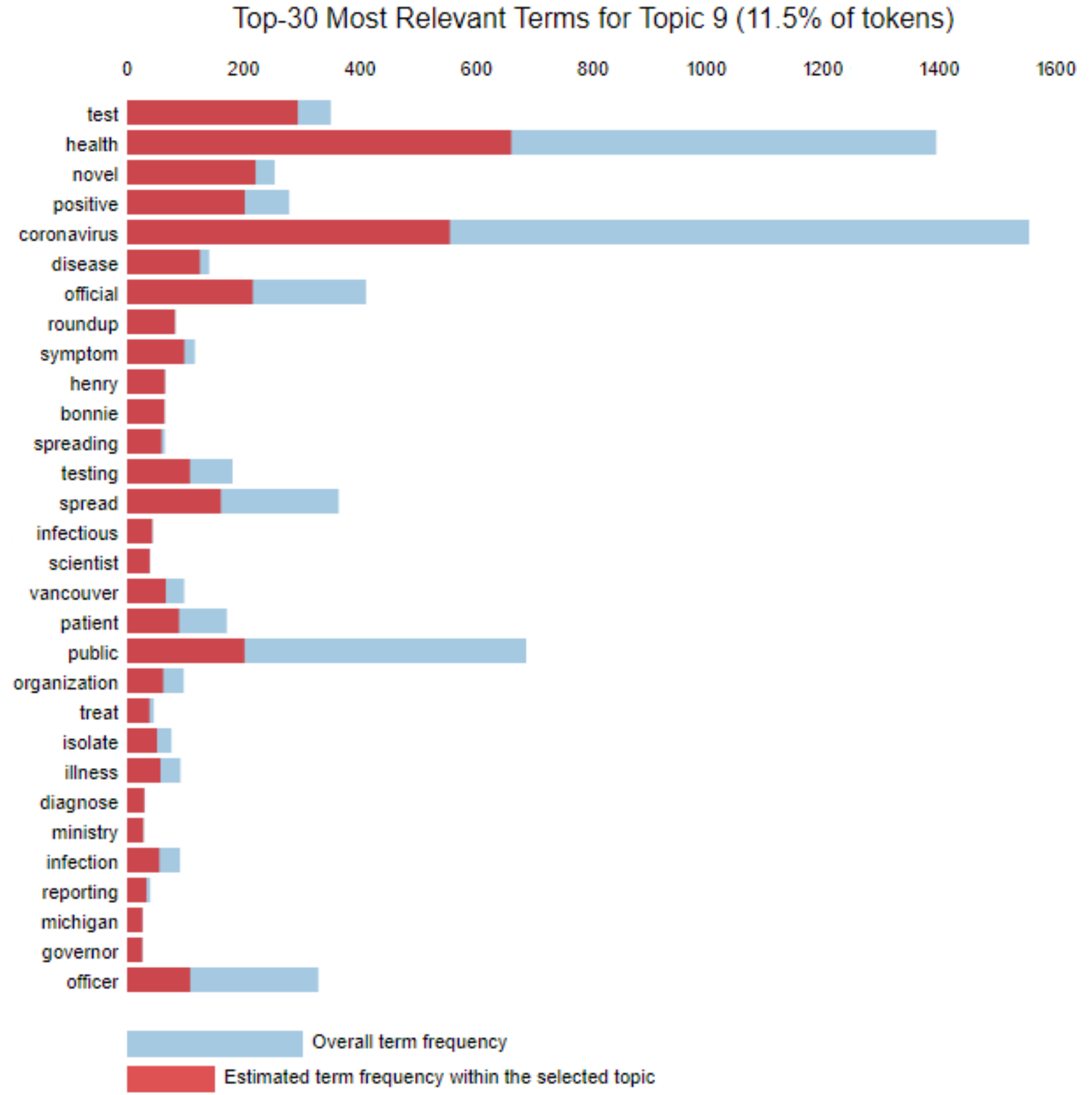


Table 1. Themes and topics $(\mathrm{N}=6771)$.

Themes and topics Number of news articles, $\mathrm{n}(\%)^{\mathrm{a}}$ Keywords

Theme 1: Case reporting and testing $(\mathrm{n}=1738)$

Topic 9: Testing

$876(12.97)$

Topic 14: Case reporting

$862(12.73)$

Theme 2: Canadian response to pandemic $(n=1259)$

Topic 5: General response

Topic 6: Health care/hospital response

Topic 10: Vaccine research

Topic 1: Medical supplies and resources

Theme 3: Changes to everyday life $(n=1171)$

Topic 2: Social gathering cancellations

Topic 8: School closure/virtual learning

$397(5.88)$

Topic 12: General lifestyle changes

$452(6.68)$

\section{Theme 4: Communication from the government $(n=1002)$}

Topic 11: Public health announcements

Topic 3: Prime Minister's addresses

\section{Theme 5: International news $(\mathrm{n}=\mathbf{8 2 6})$}

Topic 4: Articles related to news in the United 388 (5.73) States

Topic 7: Articles related to news in China

$438(6.48)$

\section{Theme 6: Government initiatives $(n=775)$}

Topic 13: Initiatives for vulnerable populations

Topic 15: Economy and business $432(6.39)$
Coronavirus, spread, public, positive, novel, official, people, health, test, covid

Province, number, confirm, total, people, report, health, death, case, covid

Pandemic, nation, member, Windsor, covid, community, family, first, local, want

Emergency, temporary, staff, state, hospital, Sudbury, worker, declare, general, covid

Ottawa, world, around, Canada, global, point, latest, covid, coronavirus, point

Canadian, ventilator, doctor, could, Canada, happening, mask, province, available, covid

Summer, pandemic, coronavirus, cancel, festival, university, event, season, covid, plant

Parent, school, family, child, learning, student, covid, equipment, worker, pandemic

People, avoid, coming, together, change, normal, covid, province, pandemic, government

Medical, chief, public, officer, health, people, province, covid, Friday

Minister, prime, Justin, Trudeau, worker, pandemic, essential, coronavirus, health, covid

Trump, unite, outbreak, state, president, country, cruise, coronavirus, Canada, Canadian

Chinese, china, outbreak, answer, Canadian, flight, morning, expert, question, expert

Shelter, homeless, social, distance, encourage, people, pandemic, covid, measure, physical

Business, economy, government, federal, pandemic, support, covid, million, premier Canada

${ }^{\mathrm{a}}$ The percentages have been calculated using the $\mathrm{N}$ value (ie, 6771).

\section{Results}

Using the pyLDAvis tool, we grouped the 15 topics into 6 themes as shown in Table 1 . Theme 1 (case reporting and testing) had the greatest number of articles $(n=1738)$, while theme 6 (government initiatives) represented the lowest number of news reports $(n=775)$. The trend in the total frequency of articles related to COVID-19 over our study time period is shown in Figure 6. 
Figure 6. Time trend for number of articles.

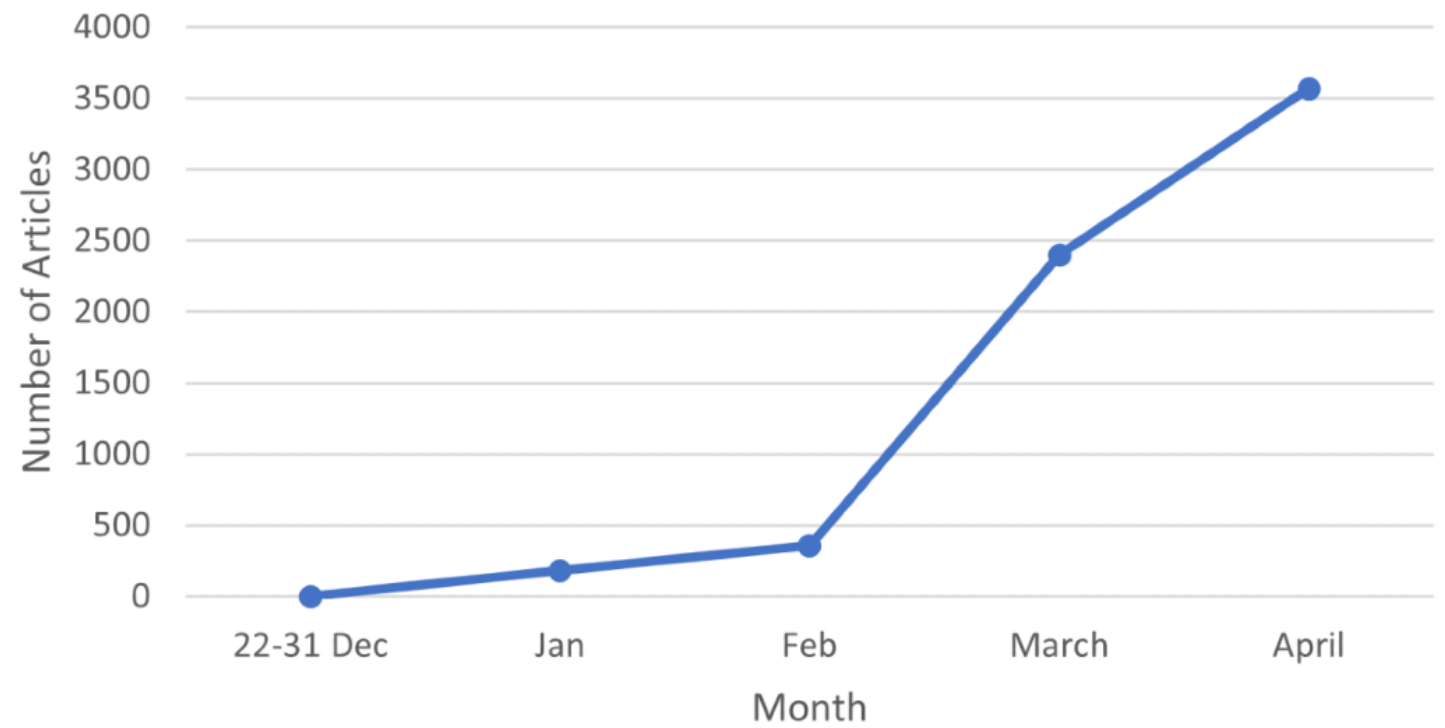

The most frequent theme, theme 1 (case reporting and testing), consisted primarily of topics that covered articles related to information about testing (12.97\%) and case reporting (12.73\%). The information in the articles related to testing focused on information regarding the tests being conducted to assess the spread of the virus, whereas the articles related to case reporting primarily focused on reporting the number of confirmed cases and deaths around the country, with words like "number," "report," "confirm," and "death" being frequently used. Similar to the trend in frequency of total articles about COVID-19, Theme 1 saw a sudden increase in the number of articles published, starting from the month of February and increasing throughout March and April (Figure 7).

Figure 7. Time trends for each theme.
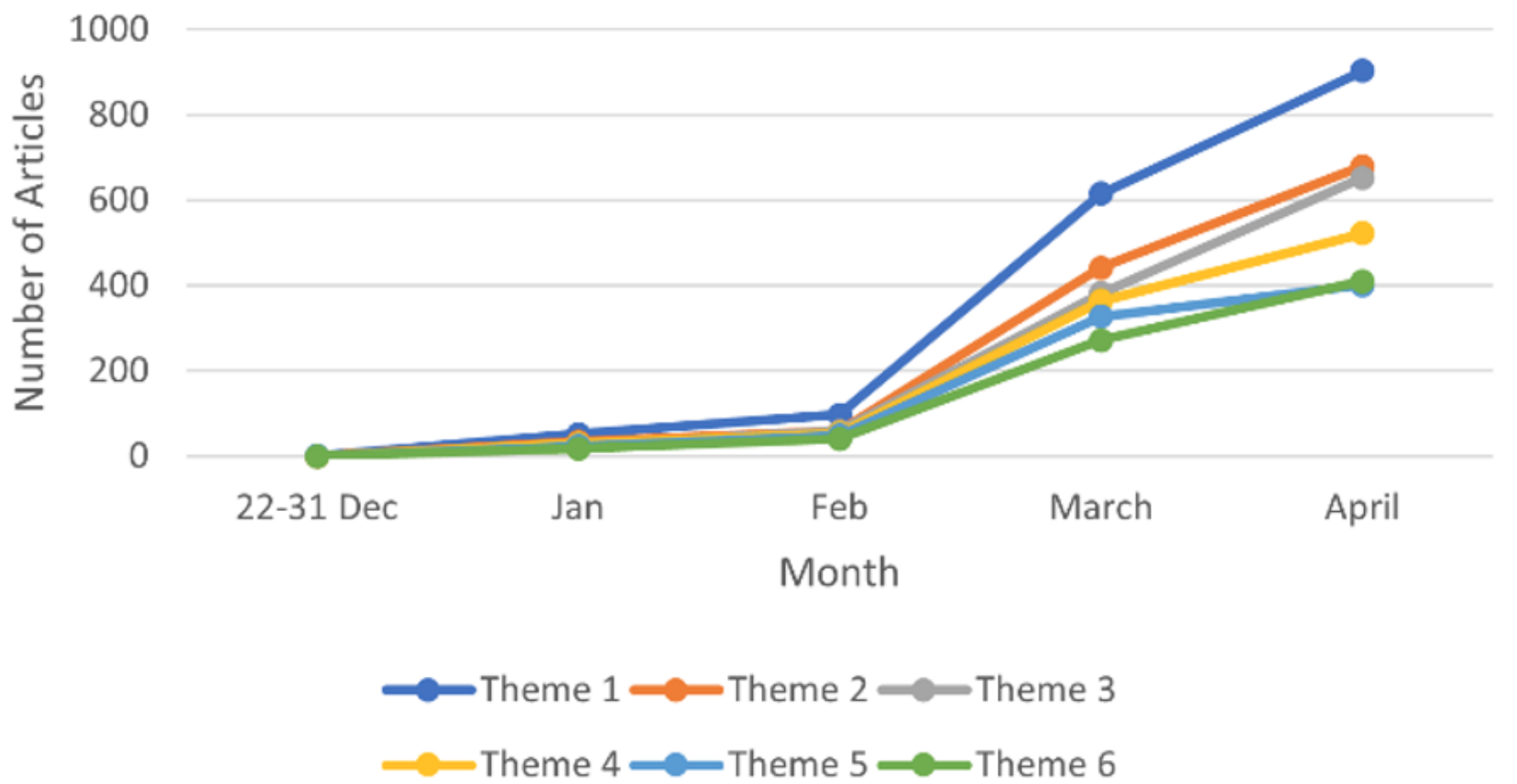

The Canadian media's focus in relation to the outbreak and Canada's response is highlighted in themes 2 and 3. Theme 2 (Canadian response to pandemic) includes topics like general response (topic 5, $\mathrm{n}=295,4.37 \%$ ), health care/hospital response (topic 6, $n=267,3.93 \%$ ), vaccine research (topic 10, $n=399$,
$5.88 \%$ ), and medical supplies and resources (topic $1, \mathrm{n}=298$, $4.40 \%$ ). Theme 3 (changes to everyday life) discusses the changes resulting from the pandemic and includes topics like social gathering cancellations (topic $2, n=322,4.76 \%$ ), school closure/virtual learning (topic $8, \mathrm{n}=397,5.88 \%$ ), and general 
lifestyle changes (topic 12, $\mathrm{n}=452,6.68 \%$ ). Both these themes saw a steep increase in the number of reported articles after the month of February.

Theme 5 (international news) consisted primarily of topics related to the United States $(n=388,5.73 \%)$ and China $(n=438$, $6.48 \%$ ). The information in articles related to the United States, Canada's geographic neighbor and largest trading partner, focused more on political relations, with frequently used words like "president," "Trump," and "state." On the contrary, the articles about China, the place of origin of the coronavirus, primarily focused on information that would enable a better understanding of the outbreak, with words like "outbreak," "question," and "answer" used more frequently.

Themes 4 and 6, although not high in frequency, focused on important themes like communication from the government and government initiatives. Communication from the government included both public health announcements as well as the Prime Minister's addresses to the public. The government initiatives theme included topics that discussed initiatives for vulnerable populations, specifically people experiencing homelessness (topic 13, $\mathrm{n}=343,5.008 \%$ ), as well as the economy and business (topic 15, $\mathrm{n}=432,6.39 \%$ ). The articles about government announcements had a steep increase leading to the declaration of pandemic in March 2020 but the slope reduced from March to April. Contrastingly, theme 6 saw a steep, consistent increase from February to April 2020.

\section{Discussion}

\section{Principal Results}

The COVID-19 pandemic has been a steep learning curve for all countries worldwide. Dissemination of information in a timely manner across communities and countries was crucial to limit the spread of COVID-19 and determine the efficacy of different treatment and management interventions. With the ensuing social isolation, online media took over as an important source of information available to the public; thus, understanding the role that the media played highlights key aspects of the challenges faced by Canada and its response to the pandemic. We used topic modelling using articles collected from the CBC's online platform and identified different themes reported through the articles.

Even though some reports about a fatal pneumonia of unknown cause had started coming out from China in early January, it was not until after the World Health Organization declared COVID-19 as a global health emergency that articles about the virus started increasing in Canada. The number of articles about COVID-19 showed a sharp increase starting February 2020 for most themes, after the World Health Organization declared it a global health emergency on January 30 . Resource shortages and panic buying have been an issue in many countries battling COVID-19 [18]. Our study identified that there were about 300 articles focused on resources. It is postulated that anxiety around sudden lockdowns and uncertainty about the duration of the pandemic might have contributed to the response of preservation of self and family [18]. Retrospectively, it would be beneficial for health care professionals, the government, and the media to work closely together to provide better guidelines and policies for the public, both to reduce anxiety and ensure more equitable distribution of resources.

Additionally, our topic modelling showed that a considerable proportion of news articles in the study focused on the conditions of marginalized populations, such as people experiencing homelessness. Many people experiencing homelessness did not receive timely shelter and space to self-isolate, putting their lives and the lives of others at risk. Thus, our study results highlight the importance of creating an equitable response strategy during future pandemics.

Throughout the course of the pandemic, the most reported information was regarding testing and case reporting. This is consistent with any communicable disease, wherein proper testing, contact tracing, and case reporting are crucial to control the spread of the disease [19]. This information can contribute to increased anxiety, as witnessed by people's fear of acquiring the disease from health care facilities, and thus being reluctant to access care for other acute illnesses, including heart attacks and strokes [20]. On the other hand, having this information could make people feel more accountable for their actions and encourage them to be more socially responsible. Although the neglect of other conditions was an unintended, unfortunate consequence of pandemic-related public health measures, for future events, more holistic communication from health care professionals (ie, about considering other acute illnesses in times of crisis) and reporting from the media on this topic could aid in better management of people with acute and chronic illnesses.

\section{Limitations}

This study only contains news articles published on CBC's online platform that were tagged with the term "coronavirus." There are several other sources of media available in Canada and future studies can focus on including multiple different sources of both digital and print media. The pandemic is ongoing and Canada's response and policies are constantly changing. Thus, doing a long-term study and constantly monitoring multiple media outlets' efforts will be helpful for future studies. This study nonetheless provides a glimpse of the Canadian media's role in the communication and dissemination of information. The LDA model has certain limitations; for example, the different topics need to be manually interpreted and are open to misinterpretation or overinterpretation. Some of its other limitations include the inability to capture correlations between topics and the use of a fixed number of topics, which must be known ahead of time.

\section{Comparison With Prior Work}

Our study identified several similar and unique themes compared to the themes identified by another similar study on Chinese media reporting [21]. Topics like case reporting, disease spread, medical supplies and resources, and research and development were similarly observed in media in both studies. However, the Chinese study did not identify any themes related to communication from the government or the country's response regarding vulnerable populations. In contrast, although lower in frequency compared to other topics, Canada's media and response focused on ensuring proper communication from the 
government and support for vulnerable populations. The government actively communicated with the public, not only through public health officials but also via regular addresses from the country's prime minister during the pandemic. Studies have shown that a leader's address to the public is very effective in reassuring people during times of crisis [22] and the media reports suggest that it played a big part in Canada's response to the pandemic.

Compared to initial communication during the $\mathrm{H} 1 \mathrm{~N} 1$ pandemic in 2009, which involved the dissemination of misinformation, leading to widespread panic, the slow dissemination of public health information by media outlets initially led to panic early in the COVID-19 pandemic. After the H1N1 pandemic, the Centers for Disease Control and Prevention conducted an audit on public health information dissemination and provided several guidelines for communications in future pandemics [23]. In line with the guidelines, our study topics found that the Canadian response had consistent messaging from federal government and public health officials; however, Canada's response still fell short with regard to prioritizing marginalized populations and reducing the public's initial stress stemming from widespread misinformation.

\section{Conclusions}

Our study highlights that, based on the topical analysis of CBC news articles, the Canadian response to the COVID-19 pandemic was a joint effort guided by government policies and communications in conjunction with people's response and adherence to protocol.

One of the most important factors in preventing the spread of COVID-19 is to empower the public with accurate information [24].

The media plays an important bridging role by relaying information from the government to the public. Thus, by understanding and analyzing the extent to which certain events and policies affect public sentiment and response, policy makers can proactively improve communication for any similar future events, including pandemics, natural disasters, or issues related to national safety.

\section{Conflicts of Interest}

None declared.

\section{References}

1. Shereen MA, Khan S, Kazmi A, Bashir N, Siddique R. COVID-19 infection: Origin, transmission, and characteristics of human coronaviruses. J Adv Res 2020 Jul;24:91-98 [FREE Full text] [doi: 10.1016/j.jare.2020.03.005] [Medline: 32257431]

2. Clark A, Jit M, Warren-Gash C, Guthrie B, Wang HHX, Mercer SW, Centre for the Mathematical Modelling of Infectious Diseases COVID-19 working group. Global, regional, and national estimates of the population at increased risk of severe COVID-19 due to underlying health conditions in 2020: a modelling study. Lancet Glob Health 2020 Aug;8(8):e1003-e1017 [FREE Full text] [doi: 10.1016/S2214-109X(20)30264-3] [Medline: 32553130]

3. Government of Canada. Coronavirus disease (COVID-19): Outbreak update. 2020. URL: https://www.canada.ca/en/ public-health/services/diseases/2019-novel-coronavirus-infection.html [accessed 2020-08-07]

4. Johns Hopkins University and Medicine. COVID-19 Dashboard by the Center for Systems Science and Engineering (CSSE) at Johns Hopkins University (JHU). 2020. URL: https://coronavirus.jhu.edu/map.html [accessed 2020-08-07]

5. Institute of Medicine (US) Committee on Assuring the Health of the Public in the 21st Century. The Future of the Public's Health in the 21st Century. Washington, DC: National Academies Press (US); 2002.

6. Fernandez MA, Desroches S, Marquis M, Lebel A, Turcotte M, Provencher V. Promoting meal planning through mass media: awareness of a nutrition campaign among Canadian parents. Public Health Nutr 2019 Oct 30;22(18):3349-3359. [doi: 10.1017/s1368980019002957]

7. CBC/Radio-Canada. Our Performance - Media Lines. 2018. URL: https://site-cbc.radio-canada.ca/site/annual-reports/ 2017-2018/accountability-plan/our-performance-media-lines-english-services-highlights-en.html [accessed 2020-08-09]

8. Han R. COVID-19 News Articles Open Research Dataset, Version 3. URL: https://www.kaggle.com/ryanxjhan/ cbc-news-coronavirus-articles-march-26 [accessed 2020-08-05]

9. Blei D, Ng A, Jordan M. Latent Dirichlet Allocation. The Journal of Machine Learning Research 2003;3:993-1022 [FREE Full text]

10. Blei D. Probabilistic topic models. Commun ACM 2012;55(4):77-84 [FREE Full text] [doi: 10.1145/2133806.2133826]

11. Jacobi C, van Atteveldt W, Welbers K. Quantitative analysis of large amounts of journalistic texts using topic modelling. Digital Journalism 2015 Oct 13;4(1):89-106 [FREE Full text] [doi: 10.1080/21670811.2015.1093271]

12. Lancichinetti A, Sirer M, Wang J, Acuna D, Körding K, Amaral L. High-Reproducibility and High-Accuracy Method for Automated Topic Classification. Phys Rev X 2015 Jan 29;5(1):1 [FREE Full text] [doi: 10.1103/physrevx.5.011007]

13. Bird S, Klein E, Loper E. Natural Language Processing with Python. Sebastopol, CA: O'Reilly Media; 2009.

14. Rehurek R, Sojka P. Software Framework for Topic Modelling with Large Corpora. In: Proceedings of the LREC 2010 Workshop on New Challenges for NLP Frameworks. 2019 Presented at: LREC 2010 Workshop on New Challenges for NLP Frameworks; May 22, 2010; Valletta, Malta p. 46-50 URL: https://is.muni.cz/publication/884893/en/ Software-Framework-for-Topic-Modelling-with-Large-Corpora/Rehurek-Sojka

15. Röder M, Both A, Hinneburg A. Exploring the Space of Topic Coherence Measures. In: Eighth ACM International Conference on Web Search and Data Mining. 2015 Feb 02 Presented at: Eighth ACM International Conference on Web Search and 
Data Mining; 2015; Shanghai, China p. 399-408 URL: https://doi.org/10.1145/2684822.2685324 [doi: 10.1145/2684822.2685324]

16. Trenquier H. Improving Semantic Quality of Topic Models for Forensic Investigation. University of Amsterdam. 2018. URL: https://www.os3.nl/_media/2017-2018/courses/rp2/p76_report.pdf [accessed 2020-07-30]

17. Sievert C, Shirley K. LDAvis: A method for visualizing and interpreting topics. In: Proceedings of the Workshop on Interactive Language Learning, Visualization, and Interfaces. 2014 Jun Presented at: Workshop on Interactive Language Learning, Visualization, and Interfaces; June 2014; Baltimore, MA. [doi: 10.3115/v1/w14-3110]

18. Sim K, Chua HC, Vieta E, Fernandez G. The anatomy of panic buying related to the current COVID-19 pandemic. Psychiatry Res 2020 Jun;288:113015 [FREE Full text] [doi: 10.1016/j.psychres.2020.113015] [Medline: 32315887]

19. Enanoria W, Liu F, Zipprich J, Harriman K, Ackley S, Blumberg S, et al. The Effect of Contact Investigations and Public Health Interventions in the Control and Prevention of Measles Transmission: A Simulation Study. PLoS One

2016;11(12):e0167160 [FREE Full text] [doi: 10.1371/journal.pone.0167160] [Medline: 27941976]

20. New data confirms significant drop in heart attack patients presenting at hospital. Heart and Stroke Foundation. URL: https:/ /www.heartandstroke.ca/what-we-do/media-centre/news-releases/ news-release-new-data-confirms-significant-drop-in-heart-attack-patients-presenting-at-hospital [accessed 2020-08-09]

21. Liu Q, Zheng Z, Zheng J, Chen Q, Liu G, Chen S, et al. Health Communication Through News Media During the Early Stage of the COVID-19 Outbreak in China: Digital Topic Modeling Approach. J Med Internet Res 2020 Apr 28;22(4):e19118 [FREE Full text] [doi: 10.2196/19118] [Medline: $\underline{\text { 32302966] }}$

22. Deitchman S. Enhancing crisis leadership in public health emergencies. Disaster Med Public Health Prep 2013 Oct;7(5):534-540. [doi: 10.1017/dmp.2013.81] [Medline: 24274133]

23. Institute of Medicine (US) Forum on Medical and Public Health Preparedness for Catastrophic Events. The 2009 H1N1 Influenza Vaccination Campaign: Summary of a Workshop Series. Washington, DC: National Academies Press (US); 2010.

24. Reddy B, Gupta A. Importance of effective communication during COVID-19 infodemic. J Family Med Prim Care 2020 Aug;9(8):3793-3796 [FREE Full text] [doi: 10.4103/jfmpc.jfmpc 719 20] [Medline: 33110769]

\title{
Abbreviations \\ CBC: Canadian Broadcasting Corporation \\ LDA: Latent Dirichlet Allocation \\ NLTK: Natural Language Toolkit
}

\author{
Edited by G Eysenbach; submitted 02.11.20; peer-reviewed by S Lin, K Reuter, S Doan; comments to author 23.12.20; revised version \\ received 06.02.21; accepted 17.04.21; published 18.07.21 \\ Please cite as: \\ Patel J, Desai H, Okhowat A \\ The Role of the Canadian Media During the Initial Response to the COVID-19 Pandemic: A Topic Modelling Approach Using Canadian \\ Broadcasting Corporation News Articles \\ JMIR Infodemiology 2021;1(1):e25242 \\ URL: https://infodemiology.jmir.org/2021/1/e25242 \\ doi: $\underline{10.2196 / 25242}$ \\ PMID: 34447922
}

CJanhavi Patel, Harsheev Desai, Ali Okhowat. Originally published in JMIR Infodemiology (https://infodemiology.jmir.org), 18.06.2021. This is an open-access article distributed under the terms of the Creative Commons Attribution License (https://creativecommons.org/licenses/by/4.0/), which permits unrestricted use, distribution, and reproduction in any medium, provided the original work, first published in JMIR Infodemiology, is properly cited. The complete bibliographic information, a link to the original publication on https://infodemiology.jmir.org/, as well as this copyright and license information must be included. 